\title{
Baculovirus Expression and Immunoreactivity of G7L Core Protein of Goatpox Virus
}

\author{
Anand Kushwaha, Amit Kumar, S. Chandra Sekar, \\ Golmei Poulinlu, Durga Goswami, Dhanavelu Muthuchelvan, \\ Muthannan Andavar Ramakrishnan and Gnanavel Venkatesan*
}

\author{
Division of Virology, ICAR-Indian Veterinary Research Institute, \\ Mukteswar, Uttarakhand-263138, India
}

*Corresponding author

\section{A B S T R A C T}

\begin{tabular}{l} 
K e y w o r d s \\
Gaotpox virus, \\
G7L, Core protein, \\
Baculovirus \\
expression vector \\
system, Insect cell \\
line, Western blot, \\
Indirect ELISA \\
Article Info \\
\hline $\begin{array}{l}\text { Accepted: } \\
\text { 14 June } 2020 \\
\text { Available Online: } \\
\text { 10 July } 2020\end{array}$ \\
\hline
\end{tabular}

Goatpox and sheeppox are highly contagious, OIE notifiable and economically important viral infections of small ruminants caused by goatpox virus (GTPV) and sheep poxvirus (SPPV) of genus Capripoxvirus, family Poxviridae. The disease is mainly endemic in central and northern Africa, Middle East and Asia including the Indian subcontinent. Several proteins of GTPV have been demonstrated to be immunogenic in nature. Out of these, G7L is a highly conserved major core protein encoded by ORF057 of GTPV genome and immunogenic in nature. The present study was designed to express full length G7L protein of GTPV using baculovirus expression vector system (BEVS) in insect cells and evaluate its diagnostic potential for detection of antibodies to GTPV. Initially, G7L gene of GTPV-Uttarkashi strain was amplified and cloned into BEVS donor vector, pFastBac ${ }^{\mathrm{TM}}$ HT A. The recombinant plasmid was confirmed by colony PCR/restriction enzyme analysis and transferred into DH10Bac cells containing baculovirus shuttle vector bacmid. The recombinant bacmid was isolated and transfected into Sf 21 cells by using cellfectin $^{\mathrm{TM}}$ reagent. Protein expression was analyzed by SDS-PAGE and confirmed by western blot as $\sim 46 \mathrm{kDa}$ in size. Recombinant G7L protein was purified by using Ni-NTA affinity chromatography under denaturing conditions and immunoreactivity of G7L protein was confirmed by using hyper immune serum of GTPV in western blot and indirect ELISA. The study confirmed immunoreactivity of recombinant G7L protein and further use as diagnostic reagent.

\section{Introduction}

Goatpox and Sheeppox are highly contagious and devastating viral systemic diseases affecting small ruminants. The infections are classified as OIE notifiable disease (OIE, 2016) based on the risk they pose to animal health and agricultural economy. Both diseases are mainly endemic in central and northern Africa, central Asia, Indian subcontinent and parts of China (Bowie et al., 2000; Babiuk et al., 2008; Bowden et al., 2009; Kitching and Carn, 2008). These are associated with high morbidity (70-90\%) and 
mortality up to $49.5 \%$ (Garner et al., 2000). Disease is more severe in young animals where mortality reaches up to $100 \%$ (Rao and Bandyopadhyay, 2000). The clinical infection is characterized by high fever, generalized pock lesions on skin and internal organs along with enlargement of superficial lymph nodes. These diseases are considered as the important constraints in the international trade of animal and their products (Babiuk et al., 2008; Madhavan et al., 2016).

The causative agents, goatpox virus (GTPV) and sheeppox virus (SPPV) belong to the genus Capripoxvirus within the subfamily Chordopoxvirinae, family Poxviridae. The genome is double-stranded DNA with $\sim 154$ kbp size. Lumpy skin disease virus (LSDV) is the other member of this genus. These three viruses exhibit 96-97\% similarity in nucleotide and amino acid sequence throughout their length (Black et al., 1986; Tulman et al., 2002; Zeng et al., 2014). They cannot be differentiated even by serological methods. During infection by poxviruses, two types of virions are produced viz. intracellular mature virion (IMV) and extracellular enveloped virion (EEV). Several membrane proteins are found on IMV and EEV virion particles. Apart from IMV and EEV membrane proteins, few proteins present on core portion of virion have been found to be immunogenic. Diagnosis of capripoxvirus infection is based on detecting the viral antigen or antibody including virus isolation, counter immunoelectrophoresis (CIE), serum neutralization test (SNT) and nucleic acid detection (Bhanuprakash et al., 2011). SNT is gold standard test for sero-diagnosis of capripoxvirus infections but it is not sufficiently sensitive to detect the low level of antibodies in animals. SNT requires handling of live virus and there is risk of accidental escape of virus into environment. The diagnostic assay based on recombinant antigen would be a better alternative. To develop recombinant protein based immunological assay many immunogenic proteins have been expressed in heterologous expression host and evaluated for diagnostic antigen (Chen et al., 2008; Bhanot et al., 2009; Bowden et al., 2009; Venkatesan et al., 2018; Dasprakash et al., 2019; Kumar et al., 2019). In this regard, herefore, the present study was designed to clone and express core protein, G7L $(\sim 46 \mathrm{kDa})$ of GTPV using baculovirus expression vector system (BEVS) in insect cells and evaluate its diagnostic potential for detection of antibody to capripoxviruses.

\section{Materials and Methods}

\section{Cells and virus}

Vero cells were maintained in Eagle's Minimum Essential Medium [Sigma, USA] with $10 \%$ fetal bovine serum. GTPV vaccine virus (Uttarkashi strain, passage 60) available in Poxvirus laboratory ICAR-IVRI, Mukteswar was grown in Vero cells and harvested after appearance of cytopathic effect (CPE) 6 days post infection. Sf-21cells [Invitrogen, USA], High-five cells and TN5 cells [Invitrogen, USA] were cultured in Sf900 III SFM [Invitrogen, USA].

\section{DNA extraction, primers and PCR}

Genomic DNA was extracted from harvested GTPV vaccine virus (Uttarkashi strain, passage 60) using Nucleo-pore ${ }^{\circledR}$ DNA extraction kit [Genetix Biotech Asia Pvt. Ltd, India] and was used as template for PCR amplification. Oligonucleotide primers targeting full-length G7L gene were designed based on GTPV FZ sequence (GenBank accession KC951854.1). The forward primer (GPBacG7F: GCCGGATCCGATGATAGAACCAAAAC AATCATCG) and reverse primer (GPBacG7R: 
GCGCTCGAGTACTTTACAGAATTTAAT CCAGGA) had added restriction sites (undelined) at 5'end for the BamHI and XhoI enzymes. From extracted genomic DNA, PCR amplification of G7L gene was done using TaKaRa Ex Taq DNA polymerase [Clontech, Takara, Japan]. PCR was carried out by initial denaturation of $95^{\circ} \mathrm{C}$ for $5 \mathrm{~min}$. followed by 35 cycles of $94{ }^{\circ} \mathrm{C}$ for $60 \mathrm{~s}, 54{ }^{\circ} \mathrm{C}$ for $60 \mathrm{~s}$, $72 \mathrm{C}$ for $90 \mathrm{~s}$ and final extension at $72 \mathrm{C}$ for 7 min.

\section{Cloning of G7L PCR product into donor plasmid vector}

The PCR product was gel purified using Nucleo-pore ${ }^{\circledR}$ gel extraction kit DNA extraction kit [Genetix Biotech Asia Pvt. Ltd, India] and cloned into BamHI and XhoI site of pFastBac $^{\mathrm{TM}}$ HT A donor plasmid vector [Invitrogen, USA]. Proper recombination and orientation of the gene was determined by colony PCR and restriction enzyme analysis. Transformation of the recombinant donor plasmid vectors into DH10Bac ${ }^{\mathrm{TM}}$ competent cells [Invitrogen, USA] was carried out as per manufacturer's instructions. Recombinant bacmid DNA was isolated by conventional method and confirmed by bacmid PCR using pUC/M13 forward and reverse primer.

\section{Transfection and isolation of recombinant baculovirus}

Recombinant bacmid DNA was transfected into Sf-21 insect cells by Cellfectin II reagent [Invitrogen, USA] using standard protocol. Supernatant containing recombinant baculovirus was harvested after 5 days posttransfection, filtered and stored at $4^{\circ} \mathrm{C}$. Recombinant baculovirus stocks were passage two times by infecting Sf-21 insect cell culture and harvesting the virus after 72 hours post-infection and further used for infection of TN5 cells for expression of G7L protein.

\section{SDS-PAGE, Western blot and optimization of $\mathrm{G} 7 \mathrm{~L}$ expression in $\mathrm{TN}-5$ cells}

The harvested recombinant protein was separated by $12 \%$ SDS-PAGE gel and transferred on to polyvinylidene fluoride (PVDF) membrane. The membrane was blocked with 3\% BSA in PBS for $1 \mathrm{hr}$ at $37^{\circ} \mathrm{C}$. After washing three times with PBS-T, the membrane was incubated with Anti- $\mathrm{HIS}_{6-}$ Peroxidase mouse monoclonal antibody (1:5000 dilution) for 1 hour at $37^{\circ} \mathrm{C}$, post wash and developed with tetramethylbenzidine (TMB) substrate [Sigma, USA]. For optimization, TN-5 cells $\left(0.8 \times 10^{6}\right.$ cells/well $)$ were seeded into 6-well cell culture plate and infected with recombinant baculovirus at serial two fold dilution and incubated for $48 \mathrm{~h}, 72 \mathrm{~h}$ and $96 \mathrm{~h}$. Infected cell lysates from different time course were analyzed in $12 \%$ polyacrylamide gel electrophoresis (SDS-PAGE) and specificity of the expressed protein was confirmed by western blot.

\section{Purification of recombinant G7L protein}

From harvested TN-5 cells showing positive expression, purification of G7L protein was done using Ni-NTA affinity chromatography under denaturing conditions. Briefly, cells pellets were washed with chilled PBS and resuspended in $5.0 \mathrm{ml}$ of $6 \mathrm{M}$ guanidine hydrochloride buffer containing protease inhibitor cocktail and phenylmethylsulfonyl fluoride (PMSF). This suspension was subjected to sonication for $2 \mathrm{~min}$ (9sec on, 9 sec off) at an amplitude $25 \%$. Cell lysate was clarified by centrifugation at $10,000 \mathrm{rpm}$ for $15 \mathrm{~min}$ in refrigerated centrifuge and supernatant subjected to purification as per standard protocol. Eluted fractions of purified protein were dialyzed against $50 \mathrm{mM}$ Tris and $100 \mathrm{mM} \mathrm{NaCl}$, analyzed by SDS-PAGE and stored at $-80^{\circ} \mathrm{C}$. 
Immunoreactivity of recombinant G7L protein in Western blot and ELISA

The recombinant protein was separated by $12 \%$ SDS-PAGE gel and transferred on to PVDF membrane. The membrane was blocked with 5\% SMP in PBS-T for 1 hour at $37^{\mathrm{a}} \mathrm{C}$. After washing three times with PBS-T, the membrane was incubated with hyper immune serum specific to GTPV (1:2 dilution) for 1 hour. Post wash, the membrane was incubated with anti-goat IgG-HRPO conjugate (1:5000 dilution) for 1 hour at $37^{\circ} \mathrm{C}$ and developed with TMB substrate [Sigma, USA]. In an indirect ELISA format, $500 \mathrm{ng}$ of purified G7L was coated in 96 well ELISA plate [Nunc, USA] followed by blocking with 5\% SMP in PBS-Tween 20. Hyperimmune serum against GTPV and SPPV was added (dilution 1:20) followed by addition of antigoat (dilution 1:16000) and anti-sheep (dilution 1:4000) HRPO conjugate. Color change was observed following addition of OPD and $3 \% \mathrm{H}_{2} \mathrm{O}_{2}$. Reaction was stopped using $1 \mathrm{M} \mathrm{H}_{2} \mathrm{SO}_{4}$ solution and reading was taken at $492 \mathrm{~nm}$.

\section{Results and Discussion}

PCR amplification, cloning and recombinant bacmid DNA generation

PCR amplification of full length G7L gene showed expected product size of $\sim 1141 \mathrm{bp}$ which was confirmed on $1 \%$ agarose gel electrophoresis (Fig. 1, Panel A). Gel purified PCR product was cloned into pFastBac ${ }^{\mathrm{TM}} \mathrm{HT}$ A donor vector and confirmed by colony PCR and restriction enzyme analysis. Restriction enzyme analysis with BamH I and Xho I enzymes showed the release of insert of 1141bp size from plasmid (Fig. 1, Panel B). Recombinant pFastBac $^{\mathrm{TM}}$ HT A donor plasmid was transformed into $\mathrm{DH} 10 \mathrm{Bac}^{\mathrm{TM}}$ competent cells and recombinant bacmid DNA containing G7L gene was isolated and confirmed by bacmid PCR. Bacmid PCR product of the expected size $3571 \mathrm{bp}$ was confirmed on $0.8 \%$ agarose gel electrophoresis (Fig. 1, Panel C).

\section{Transfection and recombinant baculovirus production}

Sf-21 cells were transfected with recombinant bacmid DNA. Cytopathic changes such as ballooning, granulation and cell detachment was observed by 3 day post-transfection (Fig. 2, Panel A and B). The culture supernatants were harvested $5^{\text {th }}$ day post transfection. Viral titres were amplified by serial passaging of recombinant virus in Sf-21 cells. These virus

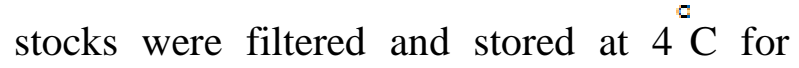
further use in infection of $\mathrm{TN}-5$ cells for protein expression analysis.

\section{Expression, optimization and purification of recombinant G7L protein of GTPV}

TN5 cell monolayers were infected with serial two-fold dilution of recombinant (Ac-GTPVG7L) virus for expression analysis. Infected cells were harvested at 48, 72 and 96 hours time intervals analyzed for expression by SDS-PAGE and western blotting. High level of protein expression was achieved at dilution 1:8 and 48 hours post infection of TN5 cells. SDS-PAGE of infected TN5 cell lysate showed the over expressed protein band of molecular weight $46 \mathrm{kDa}$ (Fig. 3, Panel A). Protein specificity was confirmed by western blotting by using Anti-HIS -Peroxidase $^{-}$ mouse monoclonal antibody.

A distinct band of $\sim 46 \mathrm{kDa}$ was observed on PVDF membrane (Fig. 3, panel B). Recombinant G7L protein was purified by using Ni-NTA affinity chromatography under denaturing conditions. Solubility analysis showed that G7L was fairly soluble in guanidine hydrochloride and was difficult to purify. 
Immunoreactivity of recombinant G7L protein

Antigenic specificity of the recombinant G7L protein was checked by reactivity with hyper immune serum of GTPV by western blotting.
A distinct size of $\sim 46 \mathrm{kDa}$ band was observed on PVDF membrane (Fig. 3, Panel C). In indirect ELISA format, the purified G7L protein reacted with GTPV and SPPV positive serum at antigen concentration of 500 ng and 1:20 serum dilution.

Fig.1 PCR amplification of G7L gene, RE digestion analysis of pFastBacHTA-G7L plasmid and confirmation of recombinant bacmid
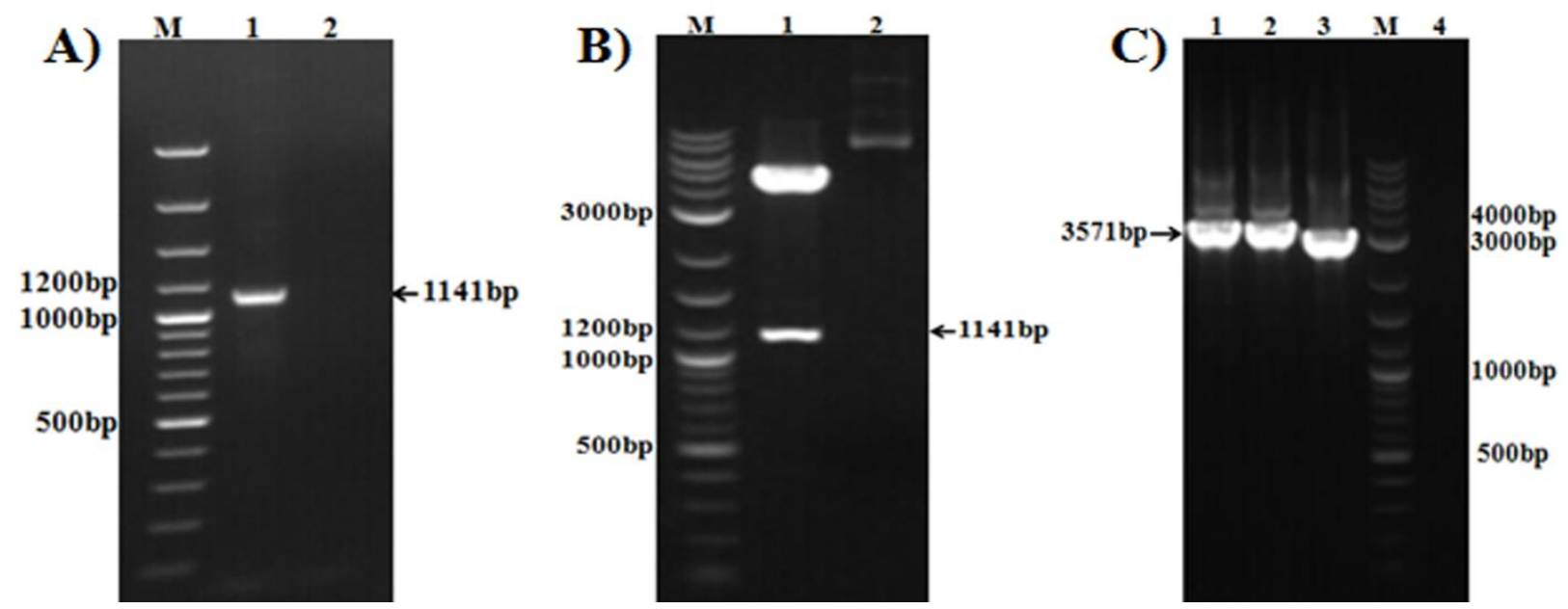

Panel A: PCR amplification of full length G7L gene. Lane M: 100 bp DNA marker; Lane 1: PCR amplicon of G7L gene (1141 bp); Lane 2: Negative control.

Panel B: RE digestion analysis of pFastBac ${ }^{\mathrm{TM}}$ HT A-G7L plasmid with BamH 1 and Xho I enzymes. Lane M: $1 \mathrm{~kb}$ DNA marker; Lane 1: pFastBac ${ }^{\mathrm{TM}}$ HT A-G7L plasmid showing release of insert (1141 bp); Lane 2: Undigested pFastBac ${ }^{\mathrm{TM}}$ HT A -G7L plasmid.

Panel C: Confirmation of recombinant bacmid by PCR with pUC/M13 primer. Lane 1, 2: PCR amplicon of recombinant bacmid (3571 bp); Lane 3: Positive control (3226 bp); Lane M: 1 kb DNA marker; Lane 4: Negative control.

Fig.2 Cytopathic effects in infected Sf-21 insect cells
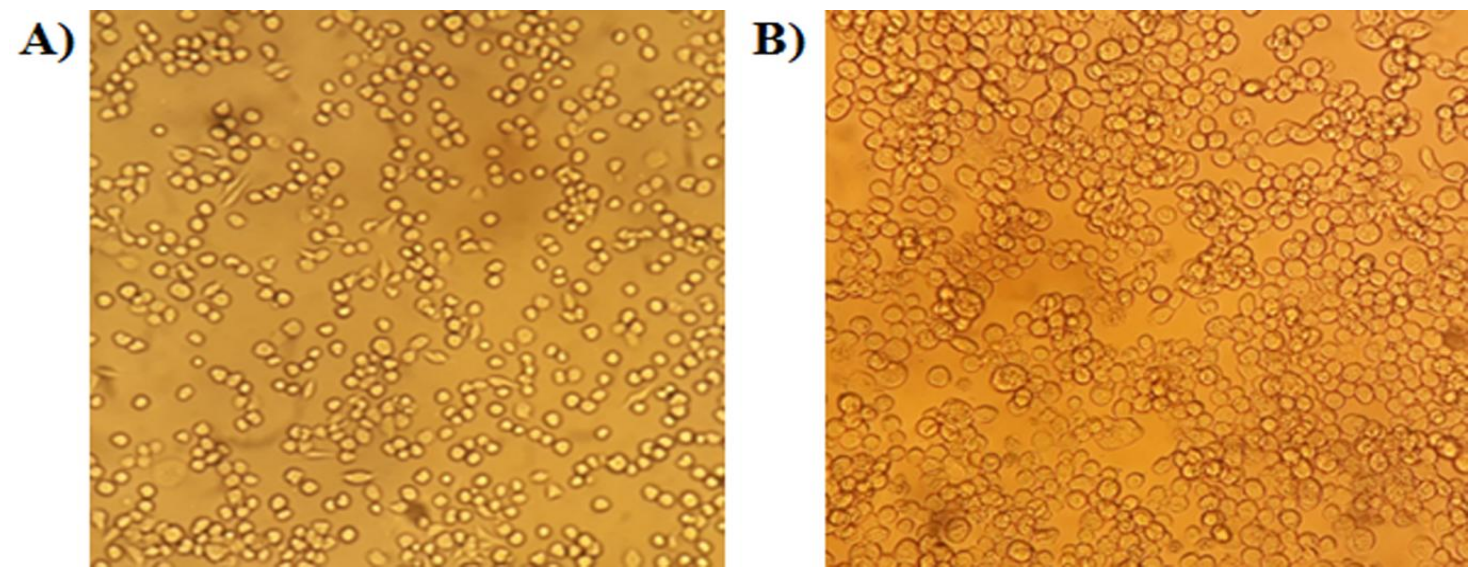

Panel A: Healthy Sf-21 insect cells.

Panel B: Sf-21 insect cells 72hours post infected showing ballooning, granulation and detachment of cells. 
Fig.3 Expression, purification and immunoreactivity of recombinant G7L protein of GTPV

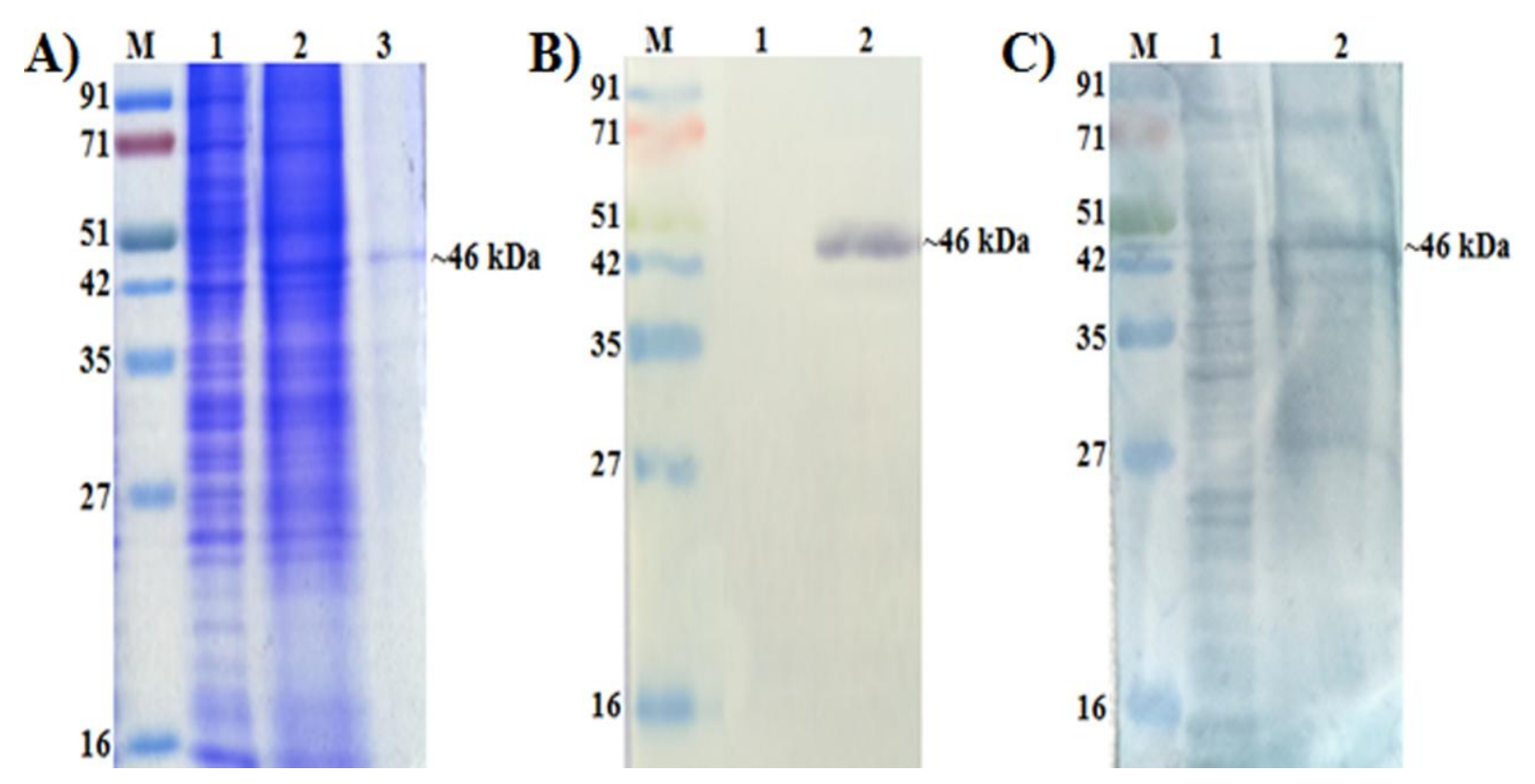

Panel A: Expression and purification of recombinant G7L protein. Lane M: Protein marker; Lane 1: Healthy TN5 cell lysate; Lane 2: Infected TN5 cell lysate showing recombinant G7L protein ( 46 kDa); Lane 3: Ni-NTA chromatography purified fraction of recombinant G7L protein.

Panel B: Western blot of recombinant G7L protein with anti- HIS $_{6}$-Peroxidase mouse monoclonal antibody. LaneM: Protein marker; Lane 1: Healthy TN-5 cell lysate; Lane 2: Infected TN5 cell lysate showing recombinant G7L $\operatorname{protein}(\sim 46 \mathrm{kDa})$.

Panel C: Western blot of recombinant G7L protein with anti-GTPV serum. Lane-M: Protein marker; Lane 1: Healthy TN5 cell lysate; Lane 2: Purified recombinant G7L protein $(\sim 46 \mathrm{kDa})$.

Goatpox and sheeppox are highly contagious and economically important viral infections of small ruminants. Disease is endemic in India and associated with high morbidity and mortality. The confirmatory diagnosis helps in control of GTPV and SPPV in endemic areas. Diagnosis of GTPV and SPPV is based on clinical signs followed by virus isolation, viral antigen or antibody detection (Bhanuprakash et al., 2011). Conventional serological test like SNT and counter immunoelectrophoresis are used for sero diagnosis but these techniques are time consuming, laborious, less sensitive and need expertise (Madhavan et al., 2016). To develop an alternative diagnostic assay with high sensitivity and specificity many approaches have been attempted using whole virus antigen based ELISA (Sharma et al., 1988) and use of recombinant protein P32 (Chen et al., 2008; Bhanot et al., 2009; Venkatesan et al., 2018), A27L (Dasprakash et al., 2019) and A12L (Bowden et al., 2009) as a potential diagnostic antigen in ELISA. There is only one study related to expression of GTPV-G7L protein in prokaryotic system (Bowden et al., 2009). However, there is no any report of expression of GTPV proteins in baculovirus expression system. In baculovirus expression system, many post translational modification including phosphorylation, glyosylation, acylation, carboxymethylation, acetylation and proteolytic cleavage have been reported (Hoss et al., 1990). Therefore, activity of recombinant protein is structurally and functionally similar to native protein. G7L is 
a core protein of GTPV and conserved among all members of the Chordopoxvirinae subfamily (Kushwaha et al., 2019).

The GTPV-G7L gene was PCR amplified, cloned into pFastBac ${ }^{\mathrm{TM}}$ HT A donor vector and successfully transformed into DH10 bac competent cell. The recombinant bacmid was isolated and characterized. For protein expression, recombinant bacmid was transfected into Sf21 insect cells using cellfectin and recombinant baculovirus was produced and characterized for expression. The expected size of expressed protein $\sim 46$ $\mathrm{kDa}$ was observed on SDS-PAGE and western blot. The optimum level of protein was achieved at dilution 1:8 and 48 hours post infection. For purification of G7L protein, protein was fairly soluble in $6 \mathrm{M}$ guanidine hydrochloride and was difficult to purify. Similar results have been reported earlier also (Bowden et al., 2009). The immunoreactivity of purified protein was confirmed by western blotting and indirect ELISA. Recombinant G7L protein reacted with GTPV and SPPV sera due to antigenic cross-reactivity across genus Capripoxvirus as reported earlier (Bowden et al., 2009). Therefore, ELISA based on recombinant protein G7L alone or along with other proteins may serve as potential diagnostic antigen for detection of antibodies to GTPV and SPPV.

Conclusively, the G7L protein of GTPV was successfully cloned, and expressed in baculovirus expression vector system. Expression level of recombinant G7L was optimized and purified by using Ni-NTA affinity chromatography under denaturing conditions. The immunoreactivity of expressed protein was demonstrated by western blot and indirect ELISA. Further optimization of purification protocol is required to obtain better yield of purified G7L protein. In future, screening of serum samples of known and unknown status may be done for optimization and development of indirect ELISA.

\section{Acknowledgements}

The authors thank the Director, Indian Veterinary Research Institute (IVRI) for providing necessary facilities to carry out this work and the staff of Pox virus laboratory, IVRI, Mukteswar, for their valuable and timely help in carrying out this work. The financial support provided by ICAR-CRP vaccines and diagnostics project is also acknowledged.

\section{References}

Babiuk, S., Bowden, T.R., Boyle, D.B., Wallace, D.B. and Kitching, R.P., 2008. Capripoxviruses: an emerging worldwide threat to sheep, goats and cattle. Transbound. Emerg. Dis. 55(7): 263-272.

Bhanot, V., Balamurugan, V., Bhanuprakash, V., Venkatesan, G., Sen, A., Yadav, V., Yogisharadhya, R. and Singh, R.K., 2009. Expression of P32 protein of goatpox virus in Pichia pastoris and its potential use as a diagnostic antigen in ELISA. J. Virol. Methods. 162(1-2): 251-257.

Bhanuprakash, V., Hosamani, M. and Singh, R.K., 2011. Prospects of control and eradication of capripox from the Indian subcontinent: a perspective. Antiviral Res. 91(3): 225-232.

Black, D.N., Hammond, J.M. and Kitching, R.P., 1986. Genomic relationship between capripoxviruses. Virus Res. 5(2-3): 277-292.

Bowden, T.R., Coupar, B.E., Babiuk, S.L., White, J.R., Boyd, V., Duch, C.J., Shiell, B.J., Ueda, N., Parkyn, G.R., Copps, J.S. and Boyle, D.B., 2009. Detection of antibodies specific for sheeppox and goatpox viruses using recombinant capripoxvirus antigens in an indirect enzyme-linked immunosorbent assay. J. Virol. Methods. 161(1): 19-29.

Bowie, A., Kiss-Toth, E., Symons, J.A., Smith, G.L., Dower, S.K. and O'Neill, L.A., 2000. A46R and A52R from vaccinia virus are antagonists of host IL-1 and toll-like receptor 
signaling. Proc. Natl. Acad. Sci. India Sect. B. Biol. Sci. 97(18): 10162-10167.

Chen, Y.X., Cai, X.P., Jing, Z.Z., Ding, J.T., Wang, Y., Meng, X.L., Zhang, Y., Jia, W.Z., Qiao, J., Yan, H.B. and Fang, Y.X., 2008. Construction, expression and immunogenicity of eukaryotic vectors based on goat pox virus P32 gene. Bing du xue bao. Chinese J. Virol. 24(2): 133-137.

Dashprakash, M., Venkatesan, G., Kumar, A., Sankar, M., Arya, S., Ramakrishnan, M.A., Pandey, A.B. and Mondal, B., 2019. Prokaryotic expression, purification and evaluation of goatpox virus ORF117 protein as a diagnostic antigen in indirect ELISA to detect goatpox. Arch. Virol. 164(4): 10491058.

Garner, M.G., Sawarkar, S.D., Brett, E.K., Edwards, J.R., Kulkarni, V.B., Boyle, D.B. and Singh, S.N., 2000. The extent and impact of sheep pox and goat pox in the state of Maharashtra, India. Trop. Anim. Health Prod. 32(4): 205-223.

Hoss, A., Moarefi, I., Scheidtmann, K.H., Cisek, L.J., Corden, J.L., Dornreiter, I., Arthur, A.K. and Fanning, E., 1990. Altered phosphorylation pattern of simian virus $40 \mathrm{~T}$ antigen expressed in insect cells by using a baculovirus vector. J. Virol. 64(10): 47994807.

Kitching, R.P. and Carn, V.M., 2008. Office International des Epizooties, Manual of Diagnostic Tests and Vaccines for Terrestrial Animals (Mammals, Birds and Bees).

Kumar, A., Venkatesan, G., Kushwaha, A., Kumar, P.S., Ramakrishnan, M.A. and Dhar, P., 2019. Expression and Purification of Recombinant Immunogenic Proteins of Goat Poxvirus in Prokaryotic System. Int. J. Curr. Microbiol. App. Sci. 8(1): 1984-1990.

Kushwaha, A., Kumar, A., Madhavan, A.,
Goswami, D., Poulinlu, G. and Venkatesan, G., 2019. Immunogenic proteins of capripox virus: Potential applications in diagnostic/prophylactic developments. H\&V. 6(6): 130.

Madhavan, A., Venkatesan, G. and Kumar, A., 2016. Capripoxviruses of small ruminants: current updates and future perspectives. Asian J. Anim. Vet. Adv. 11(12): 757-770.

OIE, 2016. Sheep pox and Goat pox. In: OIE Terrestrial Manual: 1-13.

Rao, T.V.S. and Bandyopadhyay, S.K., 2000. A comprehensive review of goat pox and sheep pox and their diagnosis. Anim. Health. Res. Rev. 1(2): 127-136.

Sharma, B., Negi, B.S., Yadav, M.P., Shankar, H. and Pandey, A.B., 1988. Application of ELISA in the detection of goat pox antigen and antibodies. Acta Virol. 32(1):65-69.

Tulman, E.R., Afonso, C.L., Lu, Z., Zsak, L., Sur, J.H., Sandybaev, N.T., Kerembekova, U.Z., Zaitsev, V.L., Kutish, G.F. and Rock, D.L., 2002. The genomes of sheeppox and goatpox viruses. J. Virol. 76(12): 6054-6061.

Venkatesan, G., Teli, M.K., Sankar, M., Kumar, A., Dashprakash, M., Arya, S., Madhavan, A., Ramakrisnan, M.A. and Pandey, A.B., 2018. Expression and evaluation of recombinant P32 protein based ELISA for sero-diagnostic potential of capripox in sheep and goats. Mol. Cell. Probes. 37: 48-54.

Zeng, X., Chi, X., Li, W., Hao, W., Li, M., Huang, X., Huang, Y., Rock, D.L., Luo, S. and Wang, S., 2014. Complete genome sequence analysis of goatpox virus isolated from China shows high variation. Vet. Microbiol. 173(1-2): 38-49.

\section{How to cite this article:}

Anand Kushwaha, Amit Kumar, S. Chandra Sekar, Golmei Poulinlu, Durga Goswami, Dhanavelu Muthuchelvan, Muthannan Andavar Ramakrishnan and Gnanavel Venkatesan. 2020. Baculovirus Expression and Immunoreactivity of G7L Core Protein of Goatpox Virus. Int.J.Curr.Microbiol.App.Sci. 9(07): 1717-1724. doi: https://doi.org/10.20546/ijcmas.2020.907.198 